\title{
Evaluation of Annual Bedding Plants for Resistance to White Mold
}

\author{
Michelle A. Grabowski ${ }^{1}$ and Dean K. Malvick \\ Department of Plant Pathology, University of Minnesota, 1991 Upper Buford \\ Circle, 495 Borlaug Hall, St. Paul, MN 55108
}

Additional index words. Sclerotinia sclerotiorum, Impatiens hawkeri, New Guinea impatiens, Impatiens walleriana, impatiens, Pentas lanceolata, Portulaca grandiflora, Moss Rose, Scaevola hybrid, Zinnia elegans $\times$ angustifolia, zinnia

\begin{abstract}
White mold, caused by the necrotrophic fungus Sclerotinia sclerotiorum (Lib.) de Bary, causes stem rot, crown rot, wilt, and death of many common herbaceous ornamental plants. Relatively little research has been done on management of white mold and resistance to this disease in ornamental crops. Plant varieties from four genera of widely available annual bedding plants with no reported history of white mold susceptibility were evaluated for potential resistance to $S$. sclerotiorum. All plants were inoculated with three isolates of $S$. sclerotiorum and evaluated for disease severity in a controlled environment and under field conditions. Portulaca grandiflora Hook. 'Sundial Scarlet', P. grandiflora 'Sundial White', Pentas lanceolata Forssk. 'Graffiti Pink', and Scaevola aemula R. Br. 'Whirlwind White' were highly susceptible to white mold in the controlled environment but had significantly lower disease incidence and severity than Zinnia elegans $\times$ angustifolia 'Profusion White', the susceptible control, under field conditions. Impatiens hawkeri W. Bull. 'Sonic Red', I. hawkeri 'Sonic Amethyst', I. hawkeri 'Sonic White', I. walleriana Hook. f. 'Blitz 3000 Red', I. walleriana 'Blitz 3000 White', and $I$. walleriana 'Blitz 3000 Rose' displayed abscission of diseased plant tissue as an unusual resistance response. Plants from all four genera that were evaluated became infected with $\boldsymbol{S}$. sclerotiorum to a lesser extent than susceptible controls under field conditions and could be used as part of an integrated disease management program for white mold in ornamental plantings.
\end{abstract}

White mold, also called Sclerotinia stem rot, is caused by the fungus Sclerotinia sclerotiorum. This necrotrophic pathogen can infect over 400 species of plants from 75 families, including monocotyledons and dicotyledons and herbaceous and woody ornamentals (Boland and Hall, 1994). Gleason et al. (2009) listed over 30 genera of herbaceous perennials and Daughtrey et al. (1995) reported 10 genera of common flowering potted plants that are susceptible to $S$. sclerotiorum. Boland and Hall (1994) list over 50 susceptible genera in asteraceae alone. These lists are outdated because multiple new publications describe infection of new host plants by S. sclerotiorum (Chang et al., 1997; Garibaldi et al., 2001, 2008a, 2008b, 2008c; Gulya et al., 2006; Strauss and Dillard, 2009).

Annual bedding plants are widely used and highly valued in landscapes in private homes, public parks, and around commercial properties. The U.S. Department of Agriculture Agricultural Statistics Service reports that the value for wholesale annual bedding and garden plants totaled $\$ 1.36$ billion in 2012 .

\footnotetext{
Received for publication 27 Oct. 2014. Accepted for publication 3 Dec. 2014.

Funding for this project was provided by the Minnesota Turf and Grounds Foundation.

This paper is a portion of a thesis by Michelle A. Grabowski in fulfilling degree requirements for the University of Minnesota.

${ }^{1}$ To whom reprint requests should be addressed; e-mailmagrabow@umn.edu.
}

Many of the most popular annual bedding plants are susceptible to white mold, including petunia, zinnia, verbena, snapdragon, and salvia (Boland and Hall, 1994). Infection of annual bedding plants can cause significant plant death in ornamental beds in home and public landscapes. Although infection may start early in the season, plant death from white mold often occurs midsummer, when replacement plants are unavailable.

Infestation of an annual flower bed with $S$. sclerotiorum is particularly problematic because the fungus produces long-term resting structures called sclerotia (Bolton et al., 2006; Grau and Radke, 1984). Once introduced, the fungus can persist in soil and plant debris for decades with repeated infection each year. The close plant spacing and overhead irrigation used in most annual plantings create highly favorable environmental conditions for sporulation and infection by $S$. sclerotiorum (Bolton et al., 2006; Grau and Radke, 1984).

Although white mold causes significant levels of stem rot, crown rot, wilt, and death of many common herbaceous ornamental plants (Bolton et al., 2006), relatively little research has been done on management of white mold in ornamental crops. Annual bedding plants are not commonly evaluated for resistance to white mold. There are several commonly used genera and species of annual bedding plants for which susceptibility or resistance to white mold has not been reported. Identification of genera or species with resistance to $S$. sclerotiorum would provide an effective means of managing white mold, requiring little extra labor or expenses. The objective of this study was to evaluate widely available annual bedding plant varieties with no reported susceptibility to white mold for potential resistance to this disease.

\section{Materials and Methods}

\section{Isolate preparation}

Three isolates of $S$. sclerotiorum from diverse hosts were arbitrarily chosen for this study. The isolates were ORN010, isolated from a petunia plant in Chaska, MN; FC002, isolated from a soybean plant in Renville County, MN; and VEG001, isolated from green bean in Spring Valley, WI. All isolates were grown on autoclaved carrots and stored as sclerotia. Sclerotia were later germinated on half-strength potato dextrose agar (PDA) (Difco, Sparks, MD) for use in inoculation trials. Isolates were never transferred on PDA more than three times between plant inoculations to maintain pathogenicity.

\section{Studies of disease susceptibility in controlled environments}

Plant species and varieties for these studies were chosen based on the known host list of S. sclerotiorum (Boland and Hall, 1994; Farr et al., 1989), the 2009 University of Minnesota annual flower trial list, and several commercial flower catalogs. Plant families were identified that had no known hosts to S. sclerotiorum, and genera of annual bedding plants within these families were chosen that are widely available to landscape managers (Table 1). The annual bedding plants were purchased in March as transplants from a local

Table 1. Plants species and varieties evaluated for susceptibility to white mold.

\begin{tabular}{|c|c|c|}
\hline Scientific name & Variety & Family \\
\hline Impatiens hawkeri & New Guinea Impatiens Sonic ${ }^{(R)}$ Red & Balsaminaceae \\
\hline Impatiens hawkeri & New Guinea Impatiens Sonic ${ }^{\mathrm{TM}}$ Amethyst '06 & Balsaminaceae \\
\hline Impatiens hawkeri & New Guinea Impatiens Sonic ${ }^{\mathrm{TM}}$ White & Balsaminaceae \\
\hline Impatiens walleriana & Impatiens Blitz 3000M Red & Balsaminaceae \\
\hline Impatiens walleriana & Impatiens Blitz $3000^{\mathrm{TM}}$ Rose & Balsaminaceae \\
\hline Impatiens walleriana & Impatiens Blitz $3000^{\mathrm{TM}}$ White & Balsaminaceae \\
\hline Pentas lanceolata & Graffiti Bright Red ${ }^{\circledR}$ & Rubiaceae \\
\hline Pentas lanceolata & Graffiti Pink $^{\circledR}$ & Rubiaceae \\
\hline Portulaca grandiflora & Moss Rose Sundial ${ }^{\mathrm{TM}}$ Scarlet & Portulacaceae \\
\hline Portulaca grandiflora & Moss Rose Sundial ${ }^{\mathrm{TM}}$ White & Portulacaceae \\
\hline Scaevola aemula & Whirlwind ${ }^{\circledR}$ White & Goodeniaceae \\
\hline Zinnia elegans $\times$ angustifolia & Profusion White & Asteraceae \\
\hline
\end{tabular}


garden center in 4-inch pots or nine packs. The plants in nine packs were transplanted into 4 -inch pots and grown in a greenhouse with12 $\mathrm{h}$ light at $25^{\circ} \mathrm{C}$ and $12 \mathrm{~h}$ dark at $20^{\circ} \mathrm{C}$ for 2 weeks before inoculation.

Studies in growth chambers were arranged in a completely random design with two factors, isolate and plant entry, replicated three times. One primary stem per plant was cut with a sterile razor blade just below the upper-most pair of fully expanded leaves. An 8-mm square of half-strength PDA containing the leading edge from a $S$. sclerotiorum culture was placed on the tip of the cut stem and covered by a sterile $0.6-\mathrm{mL}$ microcentrifuge tube. One uninoculated control plant per plant entry was prepared for inoculation in a similar fashion but received only sterile half-strength PDA. Zinnia elegans $\times$ angustifolia 'Profusion White' was included as a known susceptible control.

All plants were incubated in a mist chamber with a 12-h photoperiod and misted 10 min every hour for $2 \mathrm{~d}$ after inoculation. After $2 \mathrm{~d}$, plants were moved to a growth chamber (Environmental Growth Chambers, Chagrin Falls, OH) set to $18{ }^{\circ} \mathrm{C}$ for $14 \mathrm{~h}$ of light and $16^{\circ} \mathrm{C}$ for $10 \mathrm{~h}$ of dark. Lesion length was measured at 4 and $14 \mathrm{~d}$ after inoculation (DAI) as a rating of disease severity. As a result of a unique and unexpected resistance response of abscission of infected stems, lesion length could not be accurately measured for impatiens and New Guinea impatiens. The following scale was used to rate all impatiens: 1 - stem abscission halted progression of disease; 0 - stem abscission did not halt progression of disease.

At 14 DAI, a $2.5-\mathrm{cm}$ section of the inoculated stem centered on the leading edge of visible symptoms was excised, surfacesterilized, and plated on half-strength PDA to verify that $S$. sclerotiorum was the causal agent of the observed symptoms. The experiment was performed twice.

\section{Field studies of disease susceptibility}

All plant entries were transplanted in a randomized complete block design with six blocks at two locations in 2011 on the St. Paul campus of the University of Minnesota. Plants were purchased in 4-inch pots or nine packs from a local garden center and transplanted into one field plot on 8 June and the other field plot on 14 June. Each entry was transplanted in a $92 \mathrm{~cm} \times 92-\mathrm{cm}$ bed with $305 \mathrm{~cm}$ between plants. A single row of 'Profusion Cherry' zinnias was planted as a border around each block to help maintain even moisture within the beds and reduce edge effects. Plants were watered once a day for 20 min with an oscillating sprinkler. Osmocote 14-14-14 was applied 2 weeks after planting at a rate of $340 \mathrm{~kg} \cdot \mathrm{ha}^{-1}$ to all plots.

The three isolates of $S$. sclerotiorum noted were grown on half-strength PDA. When cultures reached the edge of a 100-mm petri plate, the agar from three plates per isolate was cut into $10-\mathrm{mm}$ squares using a sterile spatula and placed into a sterile $48 \times 58-\mathrm{cm}$ autoclavable bag (VRW Intl., Radnor, PA) containing $2000 \mathrm{cc}$ of sorghum seed. Before inoculation, sorghum seed was soaked in distilled water for 18 to $24 \mathrm{~h}$, strained to remove excess water, autoclaved for $60 \mathrm{~min}$, allowed to cool for 18 to $24 \mathrm{~h}$, and autoclaved a second time for $60 \mathrm{~min}$. The fungus was allowed to colonize the seed for 3 weeks at $23{ }^{\circ} \mathrm{C}$ and then the infested seed was dried at $35^{\circ} \mathrm{C}$ for $48 \mathrm{~h}$ and ground to a course powder in a standard blender.

Because no affect resulting from isolate was identified in the controlled environment experiments, all three isolates were combined in field studies. Inoculum was created by mixing $1000 \mathrm{cc}$ of ground seed from each of the three isolates. The inoculum mixture was then sprinkled evenly over the plant canopy by hand at a rate of $86.5 \mathrm{~L} \cdot \mathrm{ha}^{-1}$ on 4 Aug. 2011 when the trial plants had grown together to achieve canopy closure and again 1 week later. Immediately after inoculation, plants were irrigated for $5 \mathrm{~min}$. Irrigation was subsequently applied three times daily for $10 \mathrm{~min}$ for the duration of the experiment. After the inoculations, the daily maximum temperature ranged from 22.7 to $29{ }^{\circ} \mathrm{C}$ and the daily minimum temperature ranged from 15.5 to $23{ }^{\circ} \mathrm{C}$.

Disease severity and incidence were recorded every 14 DAI until frost. Disease incidence was recorded as the number of plants per bed that were visibly infected with $S$. sclerotiorum based on signs and symptoms. Any plant with questionable symptoms was surface-sterilized and plated on halfstrength PDA at the end of the experiment to determine if symptoms were caused by $S$. sclerotiorum. Disease severity was recorded as percent canopy missing as a result of death of plants within the nine plant beds. To compare disease progress over time, the summary variable area under disease progress curve was calculated for a 28-d period for Field 2 and a 42-d period for Field 1 (Madden et al., 2007). This difference in period of observation for the two fields was the result of delayed planting and an early frost in Field 2.

All varieties of $I$. walleriana were excluded from the final analysis of disease severity and incidence as a result of the confounding affects of severe infection by Plasmopara obducens, the causal organism of Impatiens Downy Mildew. Pentas lanceolata Graffiti Bright Red ${ }^{\circledR}$ was not included in the field trial as a result of a crop failure at the nursery.

Statistical analysis. Using Hartley's Fmax test, it was determined that variances were homogeneous between both controlled environment experiments. As a result, data from both experiments were combined and analyzed as a factorial design using JMP software (SAS Institute Inc., Cary, NC) to calculate an analysis of variance. Tukey's honestly significant difference was used to separate means. Uninoculated controls were not included in statistical analysis but were maintained for comparison.

Data from field experiments were not normal and treatment variance was not equal. This could not be corrected with standard data transformations. As a result, non-parametric methods were used to analyze the data. Friedman's test was used to calculate a $\chi^{2}$ for the model and a $P$ value for treatments. Treatments with a $P$ value $\leq 0.01$ were compared using Wilcoxon's rank testing to determine differences between treatments.

\section{Results}

Studies in controlled environments. All inoculated plants became infected with $S$. sclerotiorum. The pathogen was successfully isolated from all symptomatic tissue. Disease severity varied among the plants tested (Table 2). Scaevola aemula 'Whirlwind White' had significantly greater disease severity than all other genera tested except the susceptible control 'Profusion White' zinnia. Disease severity of the Portulaca grandiflora and Pentas lanceolata varieties was significantly less than the susceptible control 4 DAI, but by Day 14, there was no significant difference between disease severity in these varieties and the susceptible control (Table 2). By Day 14 of the experiment, $100 \%$ of the susceptible control plants, 'Profusion White' zinnia, were infected and lesion length extended the entire length of the stem. S. sclerotiorum was recovered from the leading edge of all lesions tested. There was no significant difference in disease severity caused by the three isolates of S. sclerotiorum. In addition, there were no significant interactions between isolate and plant entry (data not shown).

All varieties of I. hawkeri and I. walleriana developed a unique abscission resistance response to infection with $S$. sclerotiorum. Initially the inoculated stem developed soft rot at the point of inoculation, and occasionally blue-black steaks developed along the stem beyond the rotted area. This was most easily observed on varieties with green stems. At healthy nodes in advance of the infection, the plant created an abscission zone in the stem, and the stem above the abscission zone completely detached from the lower stem as shown in Figure 1. Nearly $100 \%$ of all three

Table 2. White mold lesion length ratings for annual bedding plants inoculated under controlled environment conditions.

\begin{tabular}{llcc}
\hline Scientific name & \multicolumn{1}{c}{ Variety } & $\begin{array}{c}\text { Day 4 lesion } \\
\text { length }(\mathrm{cm})\end{array}$ & $\begin{array}{c}\text { Day 14 lesion } \\
\text { length }(\mathrm{cm})\end{array}$ \\
\hline Scaevola aemula & Whirlwind ${ }^{\circledR}$ White & $7.45 \mathrm{a}^{\mathrm{z}}$ & $12.72 \mathrm{a}$ \\
Zinnia elegans $\times$ angustifolia & Profusion White & $5.99 \mathrm{~b}$ & $9.68 \mathrm{ab}$ \\
Portulaca grandiflora & Moss Rose Sundial ${ }^{\mathrm{TM}}$ White & $3.74 \mathrm{c}$ & $6.71 \mathrm{bc}$ \\
Portulaca grandiflora & Moss Rose Sundial ${ }^{\mathrm{TM}}$ Scarlet & $3.54 \mathrm{c}$ & $7.87 \mathrm{bc}$ \\
Pentas lanceolata & Graffiti Pink $^{\circledR}$ & $2.63 \mathrm{~cd}$ & $6.53 \mathrm{c}$ \\
Pentas lanceolata & Graffiti Bright Red $^{\circledR}$ & $2.22 \mathrm{~d}$ & $7.86 \mathrm{bc}$ \\
\hline
\end{tabular}

${ }^{\mathrm{z}}$ Measurements with the same letter are not significantly different at $\alpha=0.01$. 
varieties of I. hawkeri completely recovered from infection through this resistance response (Table 3 ). All varieties of I. walleriana tested also developed an abscission layer, but $S$. sclerotiorum frequently infected the lower stem before complete abscission occurred and soft rot often progressed to the crown of the plant (Table 3). S. sclerotiorum was recovered from areas of the impatiens stem with clear soft rot symptoms both above and below the abscission layer. If the plant successfully abscised the stem section containing the infection, S. sclerotiorum was not recovered from the stem below the abscission layer.

Studies under field conditions. All plant entries tested under field conditions developed infection by $S$. sclerotiorum, but incidence and severity varied (Table 4). In contrast to observations in controlled environment conditions, all varieties tested had lower disease incidence and severity compared with the susceptible control including the Scaevola hybrid. No consistent difference between plant entries was observed in disease incidence or severity. The abscission resistance response observed in Impatiens spp. under controlled environment conditions was also observed in both species in field conditions.

\section{Discussion}

This is a first report of susceptibility of Impatiens hawkeri, Impatiens walleriana, Pentas lanceolata, Portulaca grandiflora, and Scaevola aemula to white mold caused by $S$. sclerotiorum. This study shows that Scaevola aemula, Portulaca grandiflora, Pentas lanceolata, and Impatiens spp. are not immune to infection by $S$. sclerotiorum but have some resistance to infection under field conditions and suffer less canopy dieback than the susceptible control. As a result,

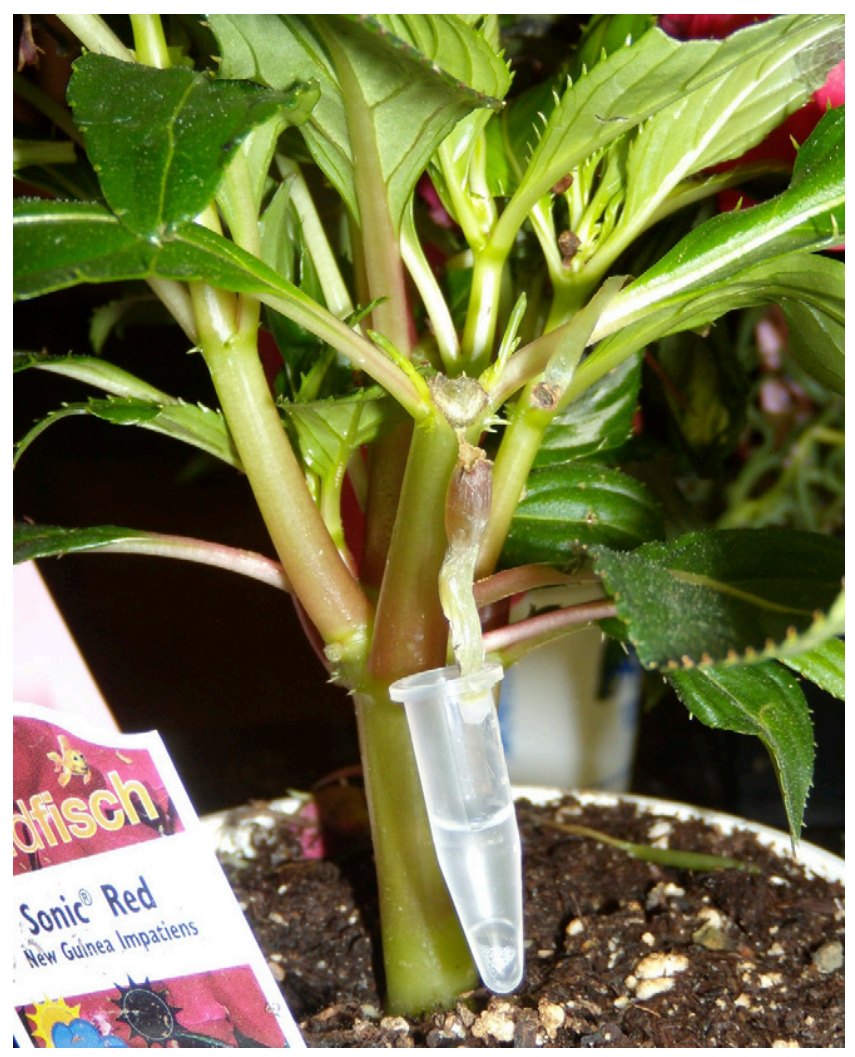

Fig. 1. Abscission of an Impatiens hawkeri stem infected with Sclerotinia sclerotiorum prevented progression of the infection further down the stem.

Table 3. Percent of impatiens plants that recovered from infection by S. sclerotiorum as a result of abscission of infected stems and the average abscission rating ${ }^{z}$ for each variety.

\begin{tabular}{|c|c|c|c|}
\hline Scientific name & Variety & $\begin{array}{l}\text { Percent plants recovered } \\
\text { from infection }\end{array}$ & $\begin{array}{l}\text { Abscission } \\
\text { rating } 14 \mathrm{DAI}\end{array}$ \\
\hline Impatiens hawkeri & $\begin{array}{l}\text { New Guinea Impatiens } \\
\text { Sonic }^{T M} \text { White }\end{array}$ & 100.0 & $1.00 \mathrm{a}^{\mathrm{y}}$ \\
\hline Impatiens hawkeri & New Guinea Impatiens Sonic ${ }^{\circledR}$ Red & 94.4 & $0.94 \mathrm{a}$ \\
\hline Impatiens hawkeri & $\begin{array}{l}\text { New Guinea Impatiens } \\
\text { Sonic }^{\top M} \text { Amethyst '06 }\end{array}$ & 94.4 & $0.94 \mathrm{a}$ \\
\hline Impatiens walleriana & Impatiens Blitz 3000 & 72.2 & $0.72 \mathrm{ab}$ \\
\hline Impatiens walleriana & Impatiens Blitz $3000^{\mathrm{TM}}$ White & 72.2 & $0.72 \mathrm{ab}$ \\
\hline Impatiens walleriana & Impatiens Blitz $3000^{\mathrm{TM}}$ Red & 50.0 & $0.50 \mathrm{~b}$ \\
\hline
\end{tabular}

${ }^{\mathrm{z}} 1=$ stem abscission halted progression of disease; $0=$ stem abscission did not halt progression of disease.

${ }^{\mathrm{y}}$ Measurements with the same letter are not significantly different at $\alpha=0.01$. landscape managers could use these plants as part of an integrated disease management plan to reduce damage from white mold. In addition, these results indicate that trials conducted in controlled environmental conditions alone are not sufficient to evaluate plant species or varieties for susceptibility to white mold.

The stem abscission observed in Impatiens spp. in response to infection with $S$. sclerotiorum was unexpected, unique, and very effective in preventing disease development. Only one other report of abscission as a defense response to $S$. sclerotiorum was found. Sedun et al. (1989) reported that abscission of infected leaf petioles of Brassica carinata in response to infection by $S$. sclerotiorum prevented the infection from spreading to the main stem. This defense response was not observed in any other Brassica sp. tested. Ethylene and jasmonic acid are known signal molecules for disease defense and abscission in plants (Dostal et al., 1991; Estornell et al., 2013; González-Carranza et al., 1998; Sequeira, 1973; Sexton, 1976; Wilson et al., 1987), and it may be beneficial to further study the role that plant hormones may play in the resistance response between Impatiens spp. and $S$. sclerotiorum.

Varieties of Scaevola aemula, Portulaca grandiflora, and Pentas lanceolata demonstrated higher levels of resistance under field conditions than in a controlled environment growth chamber. In a similar study comparing greenhouse and field inoculations of soybean, sunflower, and dry bean, Vuong et al. (2004) demonstrated a correlation between disease severity in greenhouse and field evaluations of dry bean varieties but found no correlation in sunflower and varying results for soybean. In studies evaluating field and vegetable crops, genetic resistance is often attributed to varieties that have slower lesion length development (Blanchette and Auld, 1978; Sedun et al., 1989). Varieties of Scaevola aemula, Portulaca grandiflora, and Pentas lanceolata had lesion lengths equal to susceptible control plants 14 DAI, indicating a lack of genetic resistance to $S$. sclerotiorum. However, all of these plants had significantly lower disease incidence and severity than the susceptible control under field conditions throughout the growing season.

This field resistance may be the result of plant architecture that creates an unfavorable environment for $S$. sclerotiorum in lieu of genetic defense mechanisms. Reduction of white mold disease severity resulting from plant architecture of bean has been observed in several studies (Blad et al., 1978; Park, 1993; Weiss et al., 1980). Blad et al. (1978) demonstrated that a dry bean variety with a "dense luxuriant canopy" had greater leaf wetness, cooler canopy temperature, and greater disease severity than a variety with an "open, upright growth form" with similar levels of genetic resistance. Park (1993) demonstrated that upright bean varieties had lower disease incidence than short bush types. An increase in leaf area and canopy cover of the soil was also associated with 
Table 4. Area under disease progress curve (AUDPC) for incidence and severity ${ }^{z}$ of white mold in field-inoculated annual bedding plants.

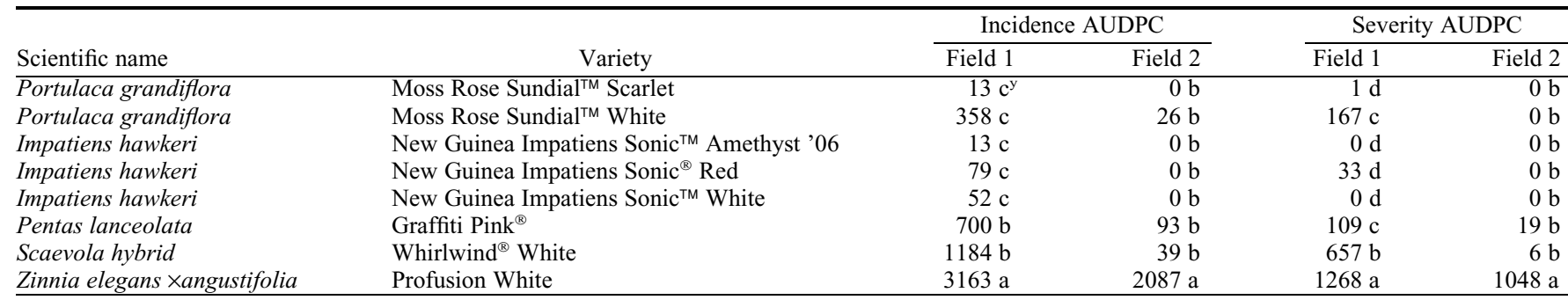

${ }^{\mathrm{z}} \mathrm{As}$ a result of delayed planting and early frost in Field 2, AUDPC was calculated over a 28-d period, whereas AUDPC for Field 1 was calculated over a 42-d period.

${ }^{\mathrm{y}}$ Measurements with the same letter are not significantly different at $\alpha=0.01$.

increased disease severity in bean crops (Blad et al., 1978; Weiss et al., 1980).

Scaevola aemula and Portulaca grandiflora both have narrow leaves that develop along recumbent stems. The overall plant canopy is open, and each individual stem receives sunlight and air movement. Soil was easily observed in beds below both plant entries in field plots indicating little shading of the soil surface. Pentas lanceolata has a tall, open upright plant form with narrow leaves and multiple branches arising from a primary stem. In contrast the susceptible control, 'Profusion white' zinnia has a short, dense, compact canopy with multiple stems grouped close together. The growth forms of Scaevola aemula, Portulaca grandiflora, and Pentas lanceolata could have accelerated the drying of stems, foliage, and soil after irrigation, rain, or dew, creating environmental conditions less favorable for infection by $S$. sclerotiorum and development of white mold.

This study reveals that various levels of resistance to white mold exist in readily available but understudied annual bedding plants. Resistance could come in the form of genetic resistance or as physical properties that make the plant a poor host. Evaluation of plants for resistance to white mold should therefore include studies under field conditions as well as in controlled environmental conditions.

\section{Literature Cited}

Blad, B.L., J.R. Steadman, and A. Weiss. 1978. Canopy structure and irrigation influence white mold disease and microclimate of dry edible beans. Phytopathology 68:1431-1437.

Blanchette, B.L. and D.L. Auld. 1978. Screening field peas for resistance to white mold. Crop Sci. 18:977-978.
Boland, G.J. and R. Hall. 1994. Index of plant hosts of Sclerotinia sclerotiorum. Can. J. Plant Pathol. 16:93-108.

Bolton, M.D., B.P.H.J. Thomma, and B.D. Nelson 2006. Sclerotinia sclerotiorum (Lib.) de Bary: Biology and molecular traits of a cosmopolitan pathogen. Mol. Plant Pathol. 7:1-16.

Chang, K.F., R.J. Howard, R.G. Gaudiel, and S.F. Hwang. 1997. First report of Sclerotinia sclerotiorum on coneflower. Plant Dis. 81:1093.

Daughtrey, M.L., R.L. Wick, and J.L. Peterson. 1995. Compendium of flowering potted plant diseases. APS Press, St. Paul, MN.

Dostal, D.L., N.H. Agnew, R.J. Gladon, and J.L. Weigle. 1991. Ethylene, simulated shipping, STS, and AOA affect corolla abscission of New Guinea impatiens. HortScience 26:4749.

Estornell, L.H., J. Agustí, P. Merelo, M. Talón, and F.R. Tadeo. 2013. Elucidating mechanisms underlying organ abscission. Plant Sci. 199200:48-60.

Farr, D.F., G.F. Bills, G.P. Chamuris, and A.Y. Rossman. 1989. Fungi on plants and plant products in the United States. APS Press, St. Paul, MN

Garibaldi, A., A. Minuto, and M.L. Gullino. 2001. First report of Sclerotinia sclerotiorum on Calendula officinalis in Italy. Plant Dis. 85:446.

Garibaldi, A., A. Minuto, and M.L. Gullino. 2008a. First report of Sclerotinia sclerotiorum on Calceolaria integrifolia in Italy. Plant Dis. 92:1133.

Garibaldi, A., P. Pensa, and M.L. Gullino. 2008b. First report of Sclerotinia sclerotiorum on Argyranthemum frutescens in Italy. Plant Dis. 92:1250.

Garibaldi, A., P. Pensa, A. Minuto, and M.L. Gullino. 2008c. First report of Sclerotinia sclerotiorum on Lantana camara in Italy. Plant Dis. 92:1369.

Gleason, M.L., M.L. Daughtrey, A.R. Chase, G.W. Moorman, and D.S. Mueller. 2009. Diseases of herbaceous perennials. APS Press, St. Paul, $\mathrm{MN}$.
González-Carranza, Z.H., E. Lozoya-Gloria, and J.A. Roberts. 1998. Recent developments in abscission: Shedding light on the shedding process. Trends Plant Sci. 3:10-14.

Grau, C.R. and V.L. Radke. 1984. Effects of cultivars and cultural practices on Sclerotinia stem rot of soybean. Plant Dis. 68:56-58.

Gulya, T.J., R.W. Gesch, C.A. Bradley, L.E. del Rio, and B.L. Johnson. 2006. First report of Sclerotinia sclerotiorum infection on Cuphea. Plant Dis. 90:1554.

Madden, L., G. Hughes, and F. van den Bosch. 2007. The study of plant disease epidemics. APS Press, St. Paul, MN.

Park, S.J. 1993. Response of bush and upright plant type selections to white mold and seed yield of common beans grown in various row widths in southern Ontario. Can. J. Plant Sci. 73:265272.

Sedun, F.S., G. Seguin-Swartz, and G.F.W. Rakow. 1989. Genetic variation in reaction to Sclerotinia stem rot in Brassica species. Can. J. Plant Sci. 69:229-232.

Sequeira, L. 1973. Hormone metabolism in diseased plants. Annu. Rev. Plant Physiol. 24:353-380.

Sexton, R. 1976. Some ultrastructural observations on the nature of foliar abscission in Impatiens sultani. Planta 128:49-58.

Strauss, J. and H.R. Dillard. 2009. First report of Sclerotinia stem rot caused by Sclerotinia sclerotiorum on Hibiscus trionum in New York. Plant Dis. 93:673.

Vuong, T.D., D.D. Hoffman, B.W. Diers, J.F. Miller, J.R. Steadman, and G.L. Hartman. 2004. Evaluation of soybean, dry bean, and sunflower for resistance to Sclerotinia sclerotiorum. Crop Sci. 44:777-783.

Weiss, A., L.E. Hipps, B.L. Blad, and J.R. Steadman. 1980. Comparison of within-canopy microclimate and white mold disease (sclerotinia sclerotiorum) development in dry edible beans as influenced by canopy structure and irrigation. Agr. Meteorol. 22:11-21.

Wilson, J.W., P.M.W. Wilson, and E.S. Walker. 1987. Abscission sites in nodal explants of Impatiens sultani. Ann. Bot. (Lond.) 60:693-704. 